Clinical Science

\title{
Single Center Experience with Endoscopic Management of Vesicoureteral Reflux in Children
}

\author{
Amir Halilbasic ${ }^{1}$ Edin Husaric ${ }^{1}$, Meliha Halilbasic $^{2}$, Senada Husaric ${ }^{3}$, Lejla Osmancevic ${ }^{1}$, Zekerija Avdic ${ }^{4}$
}

${ }^{1}$ Children's Hospital, University

Clinical Center Tuzla, Tuzla, Bosnia and Herzegovina, ${ }^{2}$ Eye Clinic, University Clinical Center Tuzla, Tuzla, Bosnia and Herzegovina, ${ }^{3} \mathrm{Clinic}$ for internal disease, University Clinical Center Tuzla, Tuzla, Bosnia and Herzegovina, ${ }^{4}$ Health Center Celic, Celic, Bosnia and Herzegovina

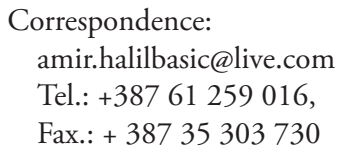

Received: Mart 31, 2019

Accepted: May 5, 2019

Key Words: Vesicoureteral Reflux (VUR) • Endoscopic Treatment - Children.

\begin{abstract}
Objective - The aim of this study was to examine the results of endoscopic treatment for vesicoureteral reflux at our institution. Patients and Methods - The study was of prospective character and included 63 patients with diagnosed vesicoureteral reflux (VUR) in a total of 87 ureters. All patients underwent endoscopic treatment using the hydrodistension implantation technique (HIT) or the subureteral transurethral injection technique (STING). Patients were observed for recurrent UTI after treatment. Fifty $(79.4 \%)$ patients had no recurrent UTI and $8(12.7 \%)$ patients underwent a second endoscopic treatment and they are now free of UTI. One patient out of the 8 required a third injection. Results - The study included 63 patients with a total of 87 ureters, treated with Dx/HA copolymer. The mean age of the patients was 5.5 years (from 1 to 14 years). Fifty - one patients were female $(80.1 \%)$ and 12 male (19.9\%). Unilateral VUR was found in 39 and bilateral in 24 patients. Fifty-three patients $(60.1 \%)$ were treated with a combination of HIT and STING procedures and $34(39.9 \%)$ patients were treated with the STING procedure only. No more than $1 \mathrm{ml} \mathrm{Dx} / \mathrm{HA}$ copolymer was injected into one ureteral orifice. No major complications were observed. Conclusion - The advantages of endoscopic treatment are short stay in hospital, no major complications and short operating time, in comparison to open surgery and it should be the first choice of treatment for patients with vesicoureteral reflux.
\end{abstract}

\section{Introduction}

Vesicoureteral Reflux (VUR) is defined as the retrograde flow of urine from the bladder back into the ureter and renal collecting system due to a failure of the ureterovesical valve mechanism (1). VUR is a common urological diagnosis that affects approximately $1 \%$ of all children, and may increase the risk of pyelonephritis and renal scarring. In children with urinary tract infection, the incidence is as high as $29 \%$ to $50 \%$. Management of vesicoureteral reflux includes open surgery, mini- mally invasive surgery, endoscopic treatment, antibiotic prophylaxis and watchful waiting. Before the introduction of endoscopic injection therapy, the mainstay of surgical treatment for VUR was open ureteral reimplantation (2). Ideally, the treatment choice should be evidence-based and may vary depending on each child's age, sex, reflux grade, history of recurrent urinary tract infection (UTI), ipsilateral renal function, associated ureterorenal anomalies, and associated bladder/bowel dysfunction, in addition to parental and provider experience and preference (3). The 
primary objective of treatment is the preservation of the kidneys and their function. Endoscopic treatment is a form of minimally invasive management of VUR and it was first described in 1981.

Currently, dextranomer/ hyaluronic acid (Dx/HA; Deflux, Oceana Therapeutics Inc., Edison, NJ, USA) is the only bulking agent approved by the U.S. Food and Drug Administration (FDA) for treating VUR, and its use increased rapidly after the approval of the Dx/HA copolymer for its use in the United States after 2001 (4). This approach corrects VUR by injecting a bulking agent to elevate and narrow the ureteral orifice and detrusor tunnel. Endoscopic injection treatment is minimally invasive, performed on an outpatient basis, and technically straightforward, with a relatively short learning curve and low complication rate $(5,6)$. In our study, we analyze the results of our experience in endoscopic treatment for vesicoureteral reflux since 2014 at the Children's Hospital, Tuzla.

The aim of this study was to examine the results of endoscopic treatment for vesicoureteral reflux at our institution.

\section{Materials and Methods}

Between October 2014 and December 2018, a total number of 63 children (87 ureters) with VUR were treated with subureteral or intraurethral injection of dextranomer/ hyaluronic acid copolymer. The radiological grading of VUR was done according to the international system introduced by the International Reflux Study Committee in 1985, whereby reflux is graded on a scale from I-V based on the degree of urine backflow and dilation of the upper tract on voiding cystourethrography (VCUG) imaging (7). The study included patients with primary reflux, without any other associated urogenital anomalies or bladder/bowel dysfunction. Per cystoscope and in general anesthesia, the needle was introduced into the urinary bladder and $1 \mathrm{ml}$ of Dx/HA copolymer was injected in the distal part of the ureter using the hydrodistension implantation technique (HIT) combined with the subureteral transurethral injection technique (STING) in most of our patients. Others were treated only by the STING procedure by injecting Dx/HA copolymer submucosally below the ureteral orifice to create a prominent bulge at the ureteral orifice. The decision on techniques used was based according to the reflux grade, degree of endoscopic hydrodistension, and the shape of the ureteral orifice. The age of our patients was between 1 and 14 years (mean age 5.5 years). Renal ultrasonography for detection of a urinary obstruction was performed 24 hours after the injection and at 1-month follow-up. VCUG was performed only in children with recurrent UTI in order to reduce radiation exposure. Successful reflux correction was defined as the absence of UTI in treated patients.

\section{Statistical Analyses}

The medical records of the treated patients were analyzed retrospectively. Standard methods of descriptive statistics were used in data analysis.

\section{Results}

The study included 63 patients with a total of 87 ureters treated with Dx/HA copolymer. The mean age of the patients was 5.5 years (from 1 to 14 years). Fifty-one patients were female (80.1\%) and 12 male (19.9\%). Unilateral VUR was found in 39 and bilateral in 24 patients. The grades of VUR in the treated ureters are presented in Fig. 1. Fifty-three patients $(60.1 \%)$ were treated with a combination of HIT and STING procedures, and $34(39.9 \%)$ patients were treated with the STING procedure alone. No more than 1 $\mathrm{ml} \mathrm{Dx} / \mathrm{HA}$ copolymer was injected into one 


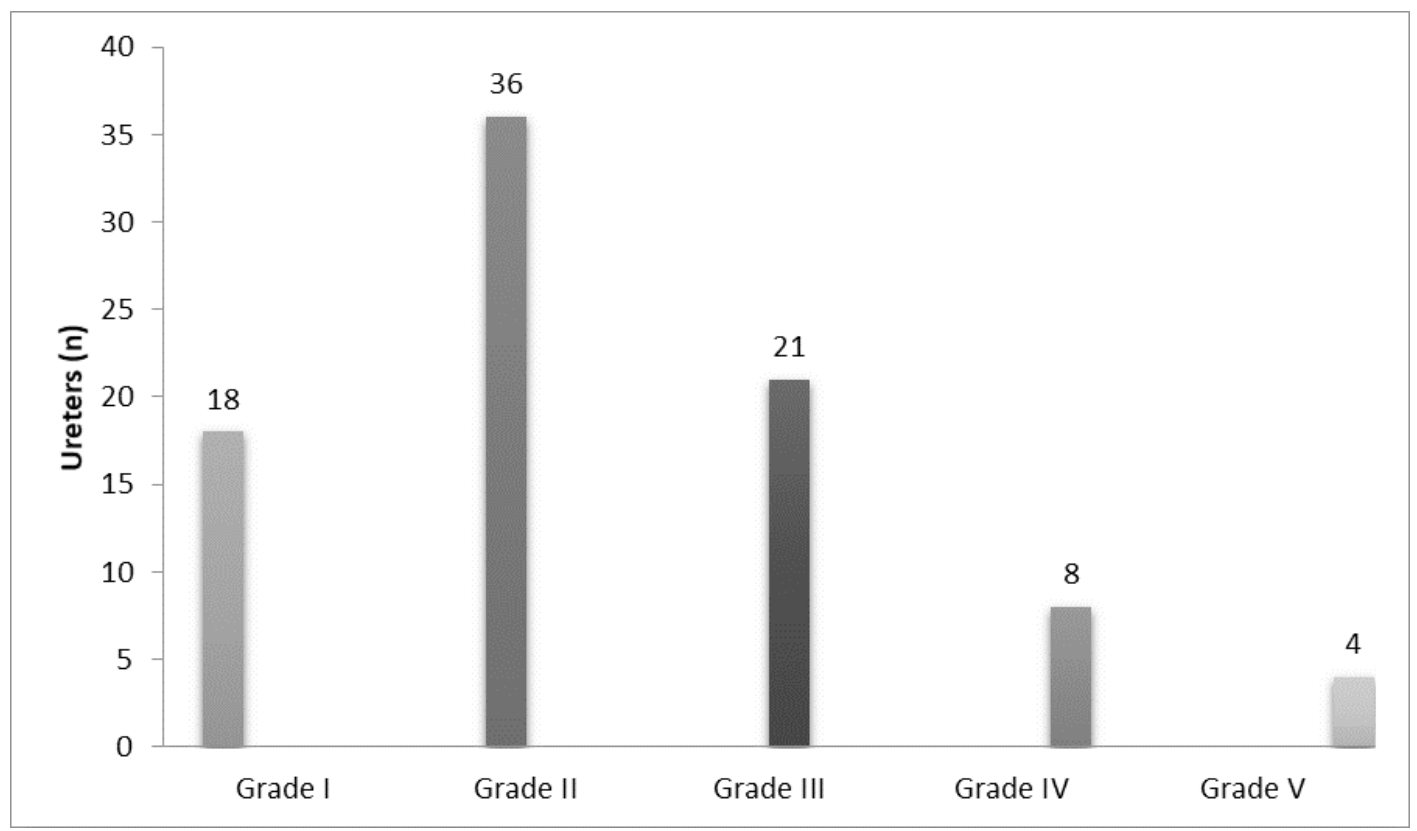

Fig. 1. Grades of VUR in Treated Ureters.

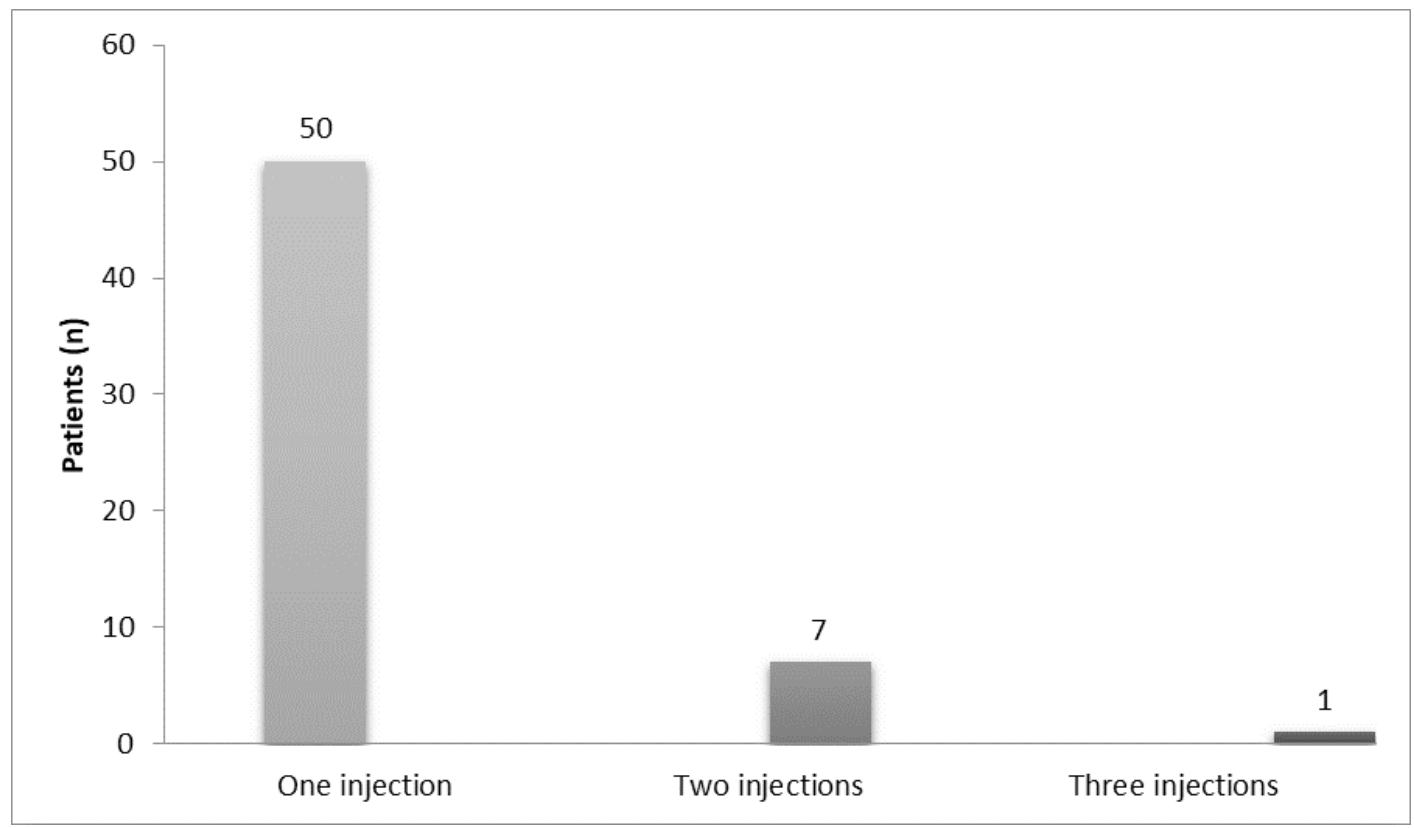

Fig. 2. Number of Repeated Procedures.

ureteral orifice. Fig. 2 shows the numbers of patients treated with a second and third endoscopic procedure.

Five (7.9\%) patients developed early transient obstruction which resolved during the first 24 hours postoperatively. On follow-up, $50(79.4 \%)$ patients had no recurrent UTI. Due to UTI recurrences and VCUG confirmation that the VUR was not resolved after the first treatment, $8(12.7 \%)$ patients un- 
derwent a second endoscopic treatment and they are now free of UTIs. One patient out of the 8 required a third injection because of VUR recurrence. No other complications were observed.

\section{Discussion}

In patients with VUR, surgical intervention may be necessary in cases with persistent reflux or recurrent pyelonephritis. In our study, the cure rate was $87.3 \% \%$ after first deflux injection, and up to $98 \%$ after a second deflux injection. The success rate in our patients is similar to the success rate reported in other studies (8-10). Lee et al. demonstrated that endoscopic treatment with dextranomer/hyaluronic acid copolymer is a safe procedure, but with a significant failure rate at 1 year, which warrants long-term follow up (11).

Our patients' mean follow-up period was 14 months and they will continue to be closely monitored in future. Early transient obstruction may be seen after endoscopic treatment of VUR, and surgeons must be aware of late hydronephrosis caused by distal ureteral obstruction which requires open surgery (12). The increase in endoscopic interventions and all its benefits in comparison with open ureteral reimplantation has led to a marked decrease in the incidence of ureteral reimplantation among children with primary VUR (13). Resolution of primary VUR secondary to Dx/HA copolymer treatment significantly improves health-related quality of life in many areas, not only in those directly associated with VUR. These improvements are not temporary, suggesting that successful Dx/HA copolymer therapy may be superior to medical management in terms of the children's quality of life (14). The advantages of this minimally invasive treatment include repeatability and the fact that postoperative complications are rare. With a second injec- tion, the success rate of endoscopic treatment approaches that of open surgery.

The minimal morbidity, short learning curve, short hospital stay and low complication rate of endoscopic treatment make it an attractive first line therapy for patients with VUR (15). Open surgery is associated with a high success rate $(>95 \%)$ regardless of the technique adopted, but because it is invasive it is limited to selected cases (16). These procedures generally require inpatient hospitalization for management of post-operative pain, as well as temporary urinary catheter drainage for several days. In contrast, endoscopic repair is an outpatient procedure with minimal post-operative pain and no need for a urinary catheter (17). At our institution endoscopic treatment has become the first line of treatment of VUR, but some cases still require open surgery. This study presents the largest reported group of patients with VUR treated with Dx/HA copolymer in our country. The results show that endoscopic treatment has good results and should be the first choice of treatment for patients with vesicoureteral reflux.

\section{Conclusion}

Endoscopic treatment's advantages are a short stay in hospital, no major complications and short operating time in comparison to open surgery. Our institution uses endoscopic treatment for primary VUR as a most comfortable method for the patient, with no concurrent morbidity.

Authors' Contributions: Conception and design: AH, $\mathrm{EH}$ and LO; Acquisition, analysis and interpretation of data: $\mathrm{MH}, \mathrm{SH}, \mathrm{AH}$ and $\mathrm{ZA}$; Drafting the article: $\mathrm{EH}$, $\mathrm{AH}, \mathrm{MH}, \mathrm{SH}$ and LO; Revising it critically for important intellectual content: AH, LO, EH, ZA; Approved final version of the manuscript: $\mathrm{MH}, \mathrm{SH}, \mathrm{AH}, \mathrm{EH}$.

Conflict of Interest: The authors declare that they have no conflict of interest. 


\section{References}

1. Lopez PJ, Celis S, Reed F, Zubieta R. Vesicoureteral reflux: current management in children. Curr Urol Rep. 2014t;15(10):447.

2. Kim SW, Lee YS, Han SW. Endoscopic injection therapy. Investig Clin Urol. 2017;58 (Suppl 1):S38-S45.

3. Kim JW, Oh MM. Endoscopic treatment of vesicoureteral reflux in pediatric patients. Korean J Pediatr. 2013;56(4):145-50.

4. Lendvay TS, Sorensen M, Cowan CA, Joyner BD, Mitchell MM, Grady RW. The evolution of vesicoureteral reflux management in the era of dextranomer/hyaluronic acid copolymer: a pediatric health information system database study. J Urol 2006; 176:1864-7.

5. Okawada M, Esposito C, Escolino M, Farina A, Cerulo $\mathrm{M}$, Turrà $\mathrm{F}$ et al. Treatment of vesico-ureteral reflux in infants and children using endoscopic approaches. Transl Pediatr. 2016 ;5(4):282-90.

6. Hajiyev P, Burgu B. Contemporary Management of Vesicoureteral Reflux. Eur Urol Focus. 2017;3(23):181-8.

7. Lebowitz RL, Olbing H, Parkkulainen KV, Smellie JM, Tamminen-Mobius TE. International system of radiographic grading of vesicoureteric reflux. International Reflux Study in Children Pediatr Radiol. 1985;15(2):105-9.

8. Pinto KJ, Pugach J, Saalfi eld J. Lack of usefulness of positioned instillation of contrast cystogram after injection of dextranomer/hyaluronic acid. Journal of Urology.2006;176(6):2654-6.

9. Yucel S, Gupta A, Snodgrass W. Multivariate analysis of factors predicting success with dextranomer/ hyaluronic acid injection for vesicoureteral reflux. J Urol. 2007;177(4):1505-9.

10. Kajbafzadeh AM, Tourchi A, Aryan Z. Factors that impact the outcome of endoscopic correction of vesicoureteral reflux: a multivariate analysis. Int Urol Nephrol. 2013;45(1):1-9.

11. Lee EK, Gatti JM, Demarco RT, Murphy JP. Longterm followup of dextranomer/hyaluronic acid injection for vesicoureteral reflux: late failure warrants continued followup. J Urol. 2009;181(4):1869-74

12. Abbo O, Bouali O, Beauval JB, Moscovici J, Galinier P. Distal and late ureteral obstruction: a rare complication following dextranomer/hyaluronic acid injection for vesicoureteral reflux in children. Prog Urol. 2012;22(3):192-4.

13. Kurtz MP, Leow JJ, Varda BK, Logvinenko T, McQuaid JW, Yu RN et al. The Decline of the Open Ureteral Reimplant in the United States:National Data From 2003 to 2013. Urology. 2017;100:1937.

14. Schwentner C, Oswald J, Lunacek A, Schlenck B, Pelzer AE, Schwentner I, et al. Health-related quality of life in children with vesicoureteral reflux impact of successful endoscopic therapy. J Pediatr Urol. 2008;4(1):20-6.

15. Routh JC, Vandersteen DR, Pfefferle H, Wolpert JJ, Reinberg Y. Single center experience with endoscopic management of vesicoureteral reflux in children. J Urol. 2006;175(5):1889-92.

16. Capozza N, Caione P. Vesicoureteral reflux: surgical and endoscopic treatment. Pediatr Nephrol. 2007;22(9):1261-5.

17. Sung J, Skoog S. Surgical management of vesicoureteral reflux in children. Pediatr Nephrol. 2011;27(4):551-61. 